\title{
Appraisal of Strategy Adopted by Construction Professionals for Coping with Stress
}

\author{
Temidayo O. Osunsanmi ${ }^{1}$, Ayodeji E. Oke ${ }^{1}$ and Clinton O. Aigbavboa ${ }^{1}$ \\ ${ }^{1}$ SARCHhI in Sustainable Construction Management and Leadership in the Built Environment, \\ Faculty of Engineering and the Built Environment. University of Johannesburg, South Africa. \\ ${ }^{*}$ Corresponding author's e-mail:osunsanmidayo@gmail.com
}

\begin{abstract}
Stress has been identified as a significant hindrance to construction professional's performance on site. Unfortunately, stress cannot be eliminated on site, but it can only be managed with different stress coping strategies. Therefore, this study aimed at appraising the strategy adopted by construction professionals for coping with stress. Although past studies have examined strategies adopted for dealing with the stress from two dimensions namely: problem-solving and emotional based stress coping strategies. This study introduced the third dimension and called it acceptance a hybrid of previous dimensions. It also appraised the strategy adopted by construction professionals for coping with stress based on their working experience. Convenience sampling method was used in gathering data from selected construction professionals in Lagos state Nigeria. A total of 62 questionnaires were obtained from the professionals out of 70 that were distributed. The data were analysed with statistical package for social science (SPSS version 24), using, mean score and Kruskal Wallis test. The findings from the Kruskal Wallis revealed that the strategy for coping with stress coping is dependent on the construction professionals working experience. The study concludes that communication is a crucial element for coping with construction stress. The study recommends that construction firms and project managers should provide opportunities for construction workers to communicate among themselves. The findings from this study will be useful for project managers and construction firms in Nigeria towards ameliorating the adverse effect of stress among construction professionals.
\end{abstract}

\section{KEYWORDS}

Construction stress; Coping strategies; Construction worker; Stress

\section{INTRODUCTION}

Bowen et al. (2014) described stress as an uncontrolled human response to social, occupational or environmental pressure. Chan et al. (2018) concluded that stress is dependent on the exposure to a stimulus in the environment that leads to emotional and cognitive imbalance. Leung et al. (2005) asserted that stress occurs due to the unfavourable condition, circumstances or tasks, an individual undertakes that. It can be deduced from the opinions related to stress that it is dependent on external factor like the working environment of an individual. 
The stress that occurs within the working environment is referred to as occupational stress or job stress (De Silva et al. 2017). According to Enshassi et al. (2018) job stress occurs when the specification and functions of a job lead to physical and emotional disturbance of an individual. Leung et al. (2015) stipulated that job stress could also occur in various forms which include: conflict among workers, technological change and many others. Lv et al. (2017) asserted that the primary driver of occupational-related stress stems from the pressure to meet the work performance criteria. This suggests that achieving optimum performance is a driver of occupational stress.

Bowen et al. (2015) meeting stipulated performance has been the mantra of the construction industry. Erik Eriksson (2010) affirmed that the construction industry is characterized by different performance criteria ranging from quality, cost and time. Towards meeting this performance criteria construction project managers are always demanding the optimum performance from construction workers. This situation leads to a heavy workload that causes a different form of stress for construction professionals (Kamardeen and Sunindijo 2017). Also, Cattell et al. (2016) concluded that the stress exhibited by construction workers occur due to the demand from clients and project managers that continually seek to ensure that work is completed on time. This infers that achieving construction project performance is the leading cause of stress among construction workers.

Chan and Leung (2011) affirmed that stress had become a common phenomenon for construction workers such that about $68 \%$ of them are constantly confronted with stress, which can be attributed to their jobs. Similarly, Chan et al. (2018) indicated that stress, confronting the construction worker is on the increase due to the ever-changing working conditions on construction sites. Kamardeen and Sunindijo (2017) attributed the stress faced by construction workers to the everyday hazards occurring on site. The author submitted that the high fatality rate of construction workers is due to the stress suffered by them on construction sites. The stress facing construction workers is often responsible for the poor performance, low employee morale and absenteeism on construction site (Enshassi and Al Swaity 2015). This opinion identifies the negative and adverse impact of stress on construction workers productivity.

However, some school of thought believed that stress facing the construction worker has a positive effect. Lv et al. (2017) opined that stress is a necessary ingredient to generate enthusiasm and creativity for optimal productivity. In support of this opinion, Enshassi et al. (2018) affirmed that stress could not be completely reduced it can only be coped with and managed. Leung et al. (2015) described stress coping as the actions adopted for handling stressful situations and activities Enshassi et al. (2018) elaborated more on stress coping and affirmed that it embraces all the deliberate actions individuals adopt to resolve personal problems with the agenda of minimising or tolerating stress. Since stress cannot be totally eliminated research into strategies adopted by construction professionals for coping with stress becomes relevant.

Although numerous research has been conducted regarding stress confronting construction professionals like: (Bowen et al. 2013; Cattell et al. 2016; Ibem et al. 2011; Leung et al. 2017). However, those studies have failed to appraise the strategies adopted by construction professionals for coping with stress. Although similar studies were conducted by (Chan et al. 2018; Enshassi et al. 2018; Naoum et al. 2018) they only evaluated the dimension of stress from the emotional and 
problem-focused approach. This study will introduce another aspect called acceptance of stress. It also differs from the past studies in the sense that it will evaluate the stress coping strategies of construction workers based on their working experience as is expected that their working experience will be a function of their stress coping strategies. The findings of the studies will be significant for construction management.

\section{STRESS WITHIN THE CONSTRUCTION INDUSTRY}

Lv et al. (2017) affirmed that stress is not attributed to a particular industry although the construction industry has a reputation for being a stressful industry. Ibem et al. (2011) opined that the stress experienced in the construction industry originates from the working condition of the industry. Likewise, Leung et al. (2017) recognised that the construction industry production process is the primary source of stress confronting construction workers. Bowen et al. (2013) stipulated that the ever-changing construction production process makes the process stressful for construction workers. This infers that the stress within the construction industry occurs at the construction stage of the project.

Cattell et al. (2016) submitted that stress occurs at the construction stage because it is characterized by uncertainty and tedious work hours. This is because the construction stage of a project is denoted with long working hours coupled with constant pressures from project managers. Ibem et al. (2011) revealed that the hazards experienced in construction sit could be related to the stress confronting construction workers. Aside from the dangers occurring on a construction site due to stress. Kamardeen and Sunindijo (2017) indicated that stress is responsible for high absenteeism of construction workers. Also, Enshassi and Al Swaity (2015) stipulated that about 90\% of construction workers absenteeism is related to the stress confronting the workers. It can be deduced that stress has a negative impact on the construction industry and it is often experienced on a construction site. Unfortunately, the stress confronting construction workers cannot be eliminated it can only be managed (Naoum et al. 2018). Therefore, the subsequent section will appraise the stress-coping dimensions.

\section{Strategies adopted for coping with stress}

According to Liao et al. (2018), coping refers to the approach adopted by an individual for adjusting to the changes in their environment. Lukowski (2015) looked at coping from another angle and concluded that all the activities undertaken by an individual to reduce the negative impact of their situation are known as coping. Enshassi et al. (2018) gave a pragmatic definition of coping as the plan utilised by an individual for managing conflicts occurring around them. It can be deduced from the aforementioned opinion that coping is subjective and depending on the external environment. Therefore, this study defines coping as the personal strategy adopted by a construction worker for managing stressful situations.

Leung et al. (2017) and Enshassi et al. (2018) classified the strategies for coping into problemfocused coping behaviour and emotion-focused behaviour. A problem-focused coping strategy is like the strategies utilised for solving a problem. Therefore, it is concerned with problem-focused efforts channelled at understanding the problem, providing alternative solutions and considering the solutions regarding its cost and benefits. Enshassi et al. (2018) stated that problem-focused strategy is concerned about evaluating the stress within. This means that when a construction 
worker attempts to provide an inward solution to the stress experienced on-site a problem-focused strategy is adopted. Lv et al. (2017) opined that problem-focused approach could be categorised into planful problem solving, positive re-appraisal, confrontive coping and seeking social support.

Emotion-focused behaviour is the second dimension of stress-coping behaviour. This form of stress coping strategy is concerned about using activities to feel better instead of utilising task. Leung et al. (2017) affirmed that emotion-focused coping approach is concerned about using a cognitive process for reducing emotional distress. Enshassi et al. (2018) declared that emotioncoping strategy aims at regulating stress occurring due to changes in emotions. This is because coping with stress using emotions provides the advantage for dealing with personal fears, anger and reaction. This implies that emotion stress coping strategy is concerned about managing stress related to feelings.

This study proposed another dimension for coping with stress management and called it acceptance. This dimension was coined after recognising that problem solving, and emotional strategy are focused on altering and adapting to the solution. Acceptance as a form of stress coping strategy recognised that the stress is beyond the control of the construction worker (Lukowski 2015). Therefore, it defined acceptance coping strategy as a form identifying stress as part of construction activity therefore given the energy to concentrate on other things. Adopting acceptance dimension for coping with stress entails: sharing feelings with other workers, learning to forgive, looking for the positive side and accepting the uncontrollable.

\section{RESEARCH METHODOLOGY}

Lagos' metropolis was identified as the study area. Lagos State was conceived as the most suitable area for the study for diverse reasons. It has remained the heart of commercial and industrial activities and has absorbed a diverse national population over the years (Bamidele et al. 2018). This has continually prompted the need for numerous construction activities within the state. Thus, registered construction professionals within Lagos Metropolis were identified and used as the study population.

The respondents within the identified population were selected through random sampling. The study adopted random sampling as it allows one to generate a smaller sample size from a larger population with the intention of generalising about the larger group (Asika 2004). Creswell and Creswell (2017) reported that random sampling works on the concept of obtaining a comprehensive list of a larger population and randomly selecting individuals to be adopted for the sample. The idea behind random sampling makes it suitable for this study due to the substantial number of construction firms in Lagos. Therefore 70 construction professionals were selected randomly, and the questionnaire was distributed to them.

The questionnaire was distributed to the selected respondents manually. A total of 62 questionnaires were retrieved from the respondents. The questionnaire was broken down into four sections with the first section examining the personal characteristics of the respondents. The subsequent sections focused on the strategies for coping with stress which is divided into problemfocused, emotion-based and acceptance strategy. The variables used to measure the strategies for coping with stress were extracted from literature such as: (Enshassi et al. 2018; Leung et al. 2017; Leung et al. 2005; Lv et al. 2017). The data from the retrieved questionnaire was analysed using 
the Statistical Package for Social Science (SPSS) version 24 using descriptive statistics such as mean item score and frequencies. This was supported with Kruskal Wallis to test whether a significant difference between the coping strategies adopted by the respondents and their working experience.

\section{ANALYSIS AND DISCUSSION}

This section presents the analysis and discussion of findings from the data collected. The section is broken down into four sections as it analyses the objectives of this study.

\section{Problem-focused coping strategy}

Problem-Focused coping strategies are presented in Table 1. The coping strategies were ranked using a five-point Likert scale from 1 representing disagree to 5 denoting strongly agree. Table 1 showed that seeking suggestion from other construction workers to solve the stress, discussing with higher authorities, adoption of innovative ideas and directing anger at the person causing the stress are the topmost strategies for coping with stress concerning problem-solving approach.

Table 1. Problem-focused coping strategies

\begin{tabular}{lll}
\hline & Mean & Rank \\
\hline Seeking suggestions or alternatives to solve the problem & 4.34 & 1 \\
I discuss with higher authorities concerning the stress & 4.27 & 2 \\
Adoption of innovative ideas to cope with the stress & 4.20 & 3 \\
Directing anger at the person causing the stress & 4.15 & 4 \\
I do other random activity to get my mind off the stress & 3.94 & 5 \\
I seek support from a senior construction worker & 3.82 & 6 \\
I learn more about the situation generating the stress & 3.75 & 7 \\
I do not act in response to the stress & 3.60 & 8 \\
\hline
\end{tabular}

\section{Emotion-based coping strategy}

Table 2 presents the emotion-based strategy adopted by construction professionals. The table shows that adopting construction work that gives satisfaction, seeking emotional support and thinking about closing time are the primary emotion-based coping strategies adopted by the construction professionals.

Table 2. Emotion-based coping strategies

\begin{tabular}{lll}
\hline & Mean & Rank \\
\hline I adopt other construction work that gives me satisfaction & 3.98 & 1 \\
I seek emotional support from other construction worker & 3.87 & 2 \\
I think about closing time & 3.76 & 3 \\
I use my religion to cope with the stress & 3.64 & 4 \\
I smoke more to cope with the stress & 3.56 & 5 \\
I put my mind off the stress & 3.46 & 6 \\
I think less about the solution of the stress & 3.32 & 7 \\
I keep the stress to myself & 3.10 & 8 \\
I use exercise to cope with stress & 2.98 & 9 \\
I eat more to cope with the construction stress & 2.84 & 10 \\
\hline
\end{tabular}


Whereas keeping the stress personally, using exercise to cope with stress and eating more to cope with construction stress are the least adopted form for coping with construction stress.

\section{Acceptance strategy for coping with stress}

Table 3 revealed the acceptance strategy adopted by the construction professionals for coping with stress. Table 3 showed that accepting stress as part of the work, taking the mind off the stress, communicating with colleagues and perceiving stress as an opportunity to learn are the major acceptance strategies for coping with stress.

Table 3. Acceptance strategy for coping with stress

\begin{tabular}{lll}
\hline & Mean & Rank \\
\hline I accept the stress as part of the work & 4.64 & 1 \\
I take my mind off the stress & 4.54 & 2 \\
I communicate with my colleagues concerning the stress & 4.23 & 3 \\
I perceive the stress as an opportunity to learn & 4.10 & 4 \\
I see construction stress as an opportunity to grow & 3.95 & 5 \\
I pass information regarding the stress to others & 3.82 & 6 \\
I discuss with my family regarding the stress & 3.75 & 7 \\
\hline
\end{tabular}

\section{Strategies for coping with stress based on working experience}

This study adopted the Kruskal Wallis test for appraising the strategy adopted by construction professionals for coping with stress based on their working experience with the outcome presented by Table 4 .

Table 4. Kruskal Wallis test for different strategies for coping with stress and working experience Dimensions for coping with stress

\begin{tabular}{ll}
\hline Chi-square & 49.671 \\
Df & 6 \\
Asymp.Sig & 0.000 \\
\hline
\end{tabular}

Grouping factor: working experience

Table 4 showed that there is a significant difference among the dimensions for coping with stress while using their working experience as a differentiating or grouping factor at a $99 \%$ confidence level. This implies that the working experience of the respondents determines the stress coping strategy adopted by the construction professionals. The finding of this study is similar to the research conducted by Leung et al. (2015) who discovered that stress coping behaviours differs according to respondents personal believes.

\section{CONCLUSION}

Stress has been discovered as one of the vital factors affecting performance and production in individuals and by extension construction workers. The study recognised that stress within the construction industry has a negative and positive impact on construction workers. Unfortunately, the negative effect of stress within the construction industry outweighs the positive effect. It was revealed from the reviewed literature that construction worker's stress is responsible for project delays, absenteeism of construction workers and hazards experienced on construction sites. Unfortunately, there has been no proven method for eliminating stress confronting construction 
workers. Therefore, this study appraised the strategies adopted by construction professionals for coping with stress.

The strategies for coping with stress revolves around three dimensions namely: problem-focused, emotion-based and acceptance. The study concludes that the form of a strategy adopted by construction professionals for coping with stress is dependent on their working experience. However, regarding the problem-focused coping approach the study revealed that seeking suggestion from other construction workers and discussing with higher authorities are the most adopted strategies. This implies that construction workers prefer communicating to solve their stress. Concerning emotion-focused strategy, the study revealed that embarking work that gives satisfaction, seeking emotional support and thinking about closing time are the most used coping strategies. Whereas for acceptance dimension of stress coping strategies the adopted strategies are: accepting stress as part of the work, taking the mind off the stress and communicating with colleagues is the predominant strategy.

The study recommends that construction firms and project managers should provide opportunities for construction workers to communicate among themselves. This is because communication was discovered as a key for effective stress coping strategy. The findings from this study will be useful for project managers and construction firms in Nigeria towards ameliorating the adverse effect of stress among construction professionals. The study could be improved upon towards developing a model for coping with stress during offsite construction.

\section{ACKNOWLEDGEMENTS}

We acknowledge the department of construction management and quantity surveying University of Johannesburg South Africa.

\section{REFERENCES}

Asika, N. (2004). "Research methodology: A process approach." Mukugamu \& Enterprises.

Bamidele, A. O., Adenusi, R., and Osunsanmi, T. O. (2018). "Towards Improved Performance in Marketing: The Use of Property-based websites by Estate Surveyors and Valuers in Lagos, Nigeria." Journal of African Real Estate Research, 3(1), 81-93.

Bowen, P., Edwards, P., and Cattell, K. "Perceptions of the relative importance of job control and support factors, as moderators of workplace stress, among South African construction professionals: Preliminary findings." Proc., Proceedings of the 31st Annual Association of Researchers in Construction Management Conference, ARCOM 2015, 479-487.

Bowen, P., Edwards, P., and Lingard, H. (2013). "Workplace stress among construction professionals in South Africa the role of harassment and discrimination." Engineering, Construction and Architectural Management, 20(6), 620-635.

Bowen, P., Edwards, P., Lingard, H., and Cattell, K. (2014). "Workplace stress, stress effects, and coping mechanisms in the construction industry." Journal of Construction Engineering and Management, 140(3).

Cattell, K., Bowen, P., and Edwards, P. (2016). "Stress among South African construction professionals: a job demand-control-support survey." Construction Management and Economics, 34(10), 700-723.

Chan, I. Y. S., and Leung, M. Y. "Impact of stress on injury incidents among construction workers." Proc., Association of Researchers in Construction Management, ARCOM 2011 - Proceedings of the 27th Annual Conference, 229-238. 
Chan, I. Y. S., Leung, M. Y., and Liang, Q. (2018). "The roles of motivation and coping behaviours in managing stress: Qualitative interview study of Hong Kong expatriate construction professionals in mainland China." International Journal of Environmental Research and Public Health, 15(3).

Creswell, J. W., and Creswell, J. D. (2017). Research design: Qualitative, quantitative, and mixed methods approaches, Sage publications.

De Silva, N., Samanmali, R., and De Silva, H. L. (2017). "Managing occupational stress of professionals in large construction projects." Journal of Engineering, Design and Technology, 15(4), 488-504.

Enshassi, A., Al-Swaity, E., Abdul Aziz, A. R., and Choudhry, R. (2018). "Coping behaviors to deal with stress and stressor consequences among construction professionals: A case study at the Gaza Strip, Palestine." Journal of Financial Management of Property and Construction, 23(1), 40-56.

Enshassi, A., and Al Swaity, E. (2015). "Key Stressors Leading to Construction Professionals' Stress in the Gaza Strip, Palestine." Journal of Construction in Developing Countries, 20(2), 53.

Erik Eriksson, P. (2010). "Improving construction supply chain collaboration and performance: a lean construction pilot project." Supply Chain Management: An International Journal, 15(5), 394403.

Ibem, E. O., Anosike, M. N., Azuh, D. E., and Mosaku, T. O. (2011). "Work stress among professionals in the building construction industry in Nigeria." Australasian Journal of Construction Economics and Building, 11(3), 46-57.

Kamardeen, I., and Sunindijo, R. Y. (2017). "Personal Characteristics Moderate Work Stress in Construction Professionals." Journal of Construction Engineering and Management, 143(10).

Leung, M. Y., Bowen, P., Liang, Q., and Famakin, I. (2015). "Development of a job-stress model for construction professionals in south Africa and Hong Kong." Journal of Construction Engineering and Management, 141(2).

Leung, M. Y., Chan, I. Y. S., and Cooper, C. L. (2015). Stress Management in the Construction Industry.

Leung, M. Y., Liang, Q., and Chan, I. Y. S. (2017). "Development of a Stressors-Stress-PerformanceOutcome Model for Expatriate Construction Professionals." Journal of Construction Engineering and Management, 143(5).

Leung, M. Y., Ng, S. T., Skitmore, M., and Cheung, S. O. (2005). "Critical stressors influencing construction estimators in Hong Kong." Construction Management and Economics, 23(1), 3343.

Liao, Y.-C., Liao, W.-Y., Sun, J.-L., Ko, J.-C., and Yu, C.-J. (2018). "Psychological distress and coping strategies among women with incurable lung cancer: a qualitative study." Supportive Care in Cancer, 26(3), 989-996.

Lukowski, A. (2015). "Coping Strategies for Stress 7 Ways To Deal With Stress."

Lv, X., Wu, X., Ci, H., Liu, Q., and Yao, Y. "Empirical research on the influencing factors of the occupational stress for construction workers." Proc., IOP Conference Series: Earth and Environmental Science.

Naoum, S. G., Herrero, C., Egbu, C., and Fong, D. (2018). "Integrated model for the stressors, stress, stress-coping behaviour of construction project managers in the UK." International Journal of Managing Projects in Business, 11(3), 761-782. 